\title{
The "aftermath" of Industry 4.0 in Small and Medium Enterprises
}

\author{
João Carlos Ferreira and João Silva ${ }^{\dagger}$ \\ *Instituto Universitário de Lisboa (ISCTE-IUL), ISTAR-IUL, Portugal \\ ${ }^{\dagger}$ Instituto Universitário de Lisboa (ISCTE-IUL), Portugal \\ jcafa@iscte-iul.pt, silva.joao.pedro.goncalves@gmail.com
}

\begin{abstract}
With the development of new technologies and methodologies, multiple sectors start to experience the benefits and drawbacks. Currently, the industry is facing a new revolution known as Industry 4.0. This new path allowed all enterprises to further develop their methodologies and understand the disadvantages and advantages of it. With the sole purpose of retaining costs in production while maintaining the same degree of quality, companies desire to diminish their downtime due to malfunction or improper maintenance schedules that may not amount to the desired efficiency. Nevertheless, not all companies manage to enter this exclusive circle, since such technologies also deliver a high cost which some companies simply cannot support. Consequently, this generates a huge drawback to the outsiders of this revolution.
\end{abstract}

\section{Keywords}

Industry 4.0 - Cyber Physical Systems

How to cite this book chapter:

Ferreira, J.C. and Silva, J. 2020. The "aftermath" of Industry 4.0 in Small and Medium Enterprises. In: Loizides, F., Winckler, M., Chatterjee, U., Abdelnour-Nocera, J. and Parmaxi, A. (eds.) Human Computer Interaction and Emerging Technologies: Adjunct Proceedings from the INTERACT 2019 Workshops. Pp. 139-144. Cardiff: Cardiff University Press. DOI: https://doi.org/10.18573/book3.q. License: CC-BY 4.0. 


\section{Introduction}

"Companies and their industrial processes need to adapt to this rapid change if they are not to be left behind by developments in their sector and by their competitors."[1]. Industries worldwide are becoming highly volatile, facing the same rhythms as their markets of choice. Taking in consideration the "big step" taken in industry regarding the systems being used, most companies face a problem regarding the data registered in their systems. Although it is collected, proper storage and analysis is not performed resulting in the incapability to extract viable knowledge crucial to decision making [2]. Consequently, this affects multiple areas of action such as maintenance, operations, etc. Therefore, companies must rapidly change their mindset to focus on the data generated to extract viable knowledge for decision making processes.

This article aims to analyze the main components that lie within Industry 4.0, advantages of its implementations and understand the main differences between SME's and MNE's. With this research the main goal is to and answer the research question: Is it possible that the main characteristics that define SME's justify the reason why they hold possible investments regarding the methodologies and practices inherent to this revolution?

\section{Industry 4.0}

Taking in consideration the developments led on during the past revolutions, a new development was needed to take full capabilities of the current information systems and produce a new output. As known, with the development of information systems in the previous revolution, data started being generated by machines in industries across the world, providing the possibility to create an automated production flow. Nevertheless, data generated was not intended to provide overall view of the production systems, more specifically to the standard maintenance point of view. Since the automation was tackled in this revolution, all the major problems regarding industry were therefore resolved. Nevertheless, the "roads" to increase earnings and productivity were decreasing. Consequently, this led to the new path of Industry 4.0. A path where the main goal was to re-shape previous ideas and concepts, allowing to reproduce models with the current technology available for industry [3].

Throughout time this concept began to grow and became a "revolution" in 2015 propagated by Germany's government as an action to maintain its position as the global leader in the sector of manufacturing equipment. At its core, one cannot state or identify what triggers industry 4.0. "Instead it can be described more precisely by a conjunction of many technologies - both existing and new which now - work together" [4]. Chesworth [5] considers that industry 4.0 is the joint effect of CPS's (Cyber Physical Sytems) and IoT (Internet of Things) therefore creating a decentralized control and advanced connec- 
Table 1: Advantages of implementing Industry 4.0 [9-10].

\begin{tabular}{|l|c|}
\hline \multicolumn{1}{|c|}{ Advantages of implementing Industry 4.0 } & Sector \\
\hline Decrease production and logistic costs by $10-30 \%$ & Costs \\
\hline Reduce Quality management costs by $10-20 \%$ & Costs \\
\hline Shorter time-to-market products & Agility/Revenues \\
\hline Improve customer responsiveness & Customer Experience \\
\hline Mass production without increasing production costs & Efficiency \\
\hline Reduce maintenance planning time (20-50\%) & Efficiency \\
\hline Increase equipment uptime (10-20\%) & Efficiency \\
\hline More confidence in data and information & Innovation \\
\hline Material cost savings (5-10\%) & Costs \\
\hline Reduce inventory carrying costs & Costs \\
\hline Reduced overall maintenance costs (5-10\%) & Costs \\
\hline
\end{tabular}

tivity. Consequently, large quantities of data are generated justifying the final component of Big Data[5, 10-11]. This joint relation constitutes the key feature of this concept, the smart factory [8].

In terms of benefits to implement the methodologies and components associated with this methodology, follows the table below.

The advantages of implementing the practices and methodologies of industry 4.0 trigger interest in all the sectors of industry, yet some already face limitations prior to generating the first step towards this new world.

\section{Industry 4.0 effect in SME}

"Small and Medium-sized Enterprises (SME's) are the driving force of many manufacturing economies"[11]. Taking in consideration their position on each country's economy, the impacts of this latest industrial revolution are important to take in consideration. Even though these aren't the only type of enterprises in the world, they face more challenges and limitations than Multi-National Enterprises (MNE's). These two types of companies differ in multiple aspects as literature states. According to the European Commission [12], SME's consist of companies with a staff headcount of 250 or less and turnover that does not exceed 50 million Euros. Nevertheless, further differences arise regarding these two types of companies. Table 2 contains the main differences regarding SME's and MNE's in an overall perspective.

As stated above, SME's due to their small size, face a tremendous limitation due to their lack of resources, both physical and financial [11]. Nevertheless, exceptions rise in specific areas such aerospace and defense. 
Table 2: Main differences between SME's and MNE's [11].

\begin{tabular}{|l|l|l|}
\hline \multicolumn{1}{|c|}{ Feature } & \multicolumn{1}{c|}{ SME's } & \multicolumn{1}{c|}{ MNE's } \\
\hline (1) Financial Resources & Low & High \\
\hline (2) Use of advanced Manufacturing & Low & High \\
\hline (3) Research and Development & Low & High \\
\hline (4) Human Resources Engagement & Multiple domains & Specific domains \\
\hline (5) Knowledge and Experience & $\begin{array}{l}\text { Focused in a } \\
\text { specific area }\end{array}$ & $\begin{array}{l}\text { Spread around } \\
\text { different areas }\end{array}$ \\
\hline (6) Important activities & Outsourced & Internal \\
\hline (7) Alliances with Universities & Low & High \\
\hline (8) Organization culture & Low & High \\
\hline
\end{tabular}

Regarding financial sector (1), one of most vital sectors in these companies, a significant disparity lays between the two types of companies. For starters, SME's that want to obtain finance must face expensive process handlings. In other words, the cost of applying for a lone are nothing but immoderate. Legal fees, administrative costs and costs related regarding information related to the acquisition are fixed, regardless of the amount to be loaned. Further costs must be applied in the presence of outside financiers. All these points together with lack of information and proper financial facilities in developing countries leads to a more severe problem.

The low amount of financial resources leads to a chain of consequences, that can be described as a snowball effect for the SME's. In terms of advanced manufacturing (2), the usage is considered low, since the investment in advanced manufacturing technologies is difficult to support. This lack of usage leads to incapability to invest in research and development (3). This deeply affects the human resources sector. Instead, the engagement of human resources (4) is in multiple domains, "For example, the employees at SME's are more likely to be 'Jack of all Trades' and less likely to develop high levels of expertise" [11]. This leads to the fact that operators in SME's do not manage to gain a proper specialization in a specific area (5), since the responsibilities inherited can range to multiple areas. This type of example does not present in MNE's due to their rich mass of employees. In these types of enterprises, the chances of an employee specialization in a certain area are higher due to sole focus performing related tasks [11].

The consequences of this methodology can easily be applied to production. A low skillset, and engagement lead to the outsourcing of production (6) to control costs and time. Due to inability to attain a proper specialization, SME's no longer sustain a proper platform to attract universities and institutes. Consequent to this lack of self-updating policy to maintain up-to-date and cutting-edge methodologies leads to SME's not being able to generate alliances with universities and institutes (7). 
With the financial, human resources and production sectors affected by this snowball link, the structure of the company is going to "feel" the consequences. With the outsourcing of production and low skill of collaborators, the company culture (8) become poor with low capability to dynamize [11].

These can be stated as the most relevant aspects in a theoretical stand point. Nevertheless, they do not differ from the main studies performed in conducted to SME's. According to the digital business readiness study, "Many enterprises are lacking financial and often human resource too, to promote digital change internally" [5]. This leads a low level of completely digitally up-to-date enterprises of $27 \%$. The main reason behind this low percentage can be explained with the fact that "SME's are lacking confidence in information security and data protection. Without this confidence, the transformation of business and manufacturing processes threatens to stall” [13].

\section{Conclusions}

From the analysis conducted throughout this paper regarding Industry 4.0 and main features of SME's and MNE's it is possible to understand the main reasons that support the lack of investment in new technologies. Latest achievements regarding methodologies and practices require a solid foundation and finance, to provide a sustainable growth for SME's which justifies the holdback from SME's.

Due to their lack of positioning in current markets, which are more and more competitive, these companies desire fast solutions to their problems, therefore maintaining methodologies that MNE's tested and approved throughout the years. Due to their capability to shape-shift into their desired solution, these companies must face the output of the market in a short-term basis, therefore invalidating the main basis of thought regarding industry 4.0. This line of thought regards a long-term vision where hefty finance is a fixed variable in the equation of going a step towards new income. SME's behave in a solid perspective where they "Don't take a step bigger than their leg". Nonetheless, this strategy to maintain position may provide negative consequences, more considerably inadequate health in a long-term statement, due to their lack of capability to self-innovate and achieve new competitive advantages. Therefore, this confirms the simple line of survival, where the runt of the litter dies.

For SME's to enter this revolution without compromising their structure they must understand the possible implementations that allow to achieve the best results with a low initial investment. This step is vital to stop the snowball effect described in this paper. One possible solution is the creation of a new framework. In other words, by providing a "step-by-step" approach, vital information can be attained in a simplified way allowing SME's to understand prior to implementation phase which elements of Industry 4.0 can be implemented and how. 


\section{References}

1. C. Finance, "Deloitte - Industry 4.0 Challenges and Solutions for Digital Transformation," 2015.

2. K. Efthymiou, N. Papakostas, D. Mourtzis, and G. Chryssolouris, "On a predictive maintenance platform for production systems," Procedia CIRP, vol. 3, no. 1, pp. 221-226, 2012.

3. N. Sakib and T. Wuest, "Challenges and Opportunities of Condition-based Predictive Maintenance: A Review," Procedia CIRP, vol. 78, pp. 267-272, 2018.

4. H. Meissner, R. Ilsen, and J. C. Aurich, "Analysis of Control Architectures in the Context of Industry 4.0," Procedia CIRP, vol. 62, pp. 165-169, 2017.

5. D. Chesworth, "Industry 4.0 Techniques as a Maintenance Strategy (A Review Paper)," Researchgate.net/publication/322369285, no. January, pp. $0-8,2018$.

6. A. T. Jones, D. Romero, and T. Wuest, "Modeling agents as joint cognitive systems in smart manufacturing systems," Manuf. Lett., vol. 17, pp. 6-8, 2018.

7. S. Ferreiro, E. Konde, S. Fernández, and A. Prado, "INDUSTRY 4.0 : Predictive Intelligent Maintenance for Production Equipment," Eur. Conf. Progn. Heal. Manag. Soc., pp. 1-8, 2016.

8. Shiyong Wang, Jiafu Wan, Di Li, and Chunhua Zhang, "Implementing Smart Factory of Industrie 4.0: An Outlook," Int. J. Distrib. Sens. Networks, vol. 2016, 2016.

9 C. Coleman, S. Damofaran, and E. Deuel, "Predictive maintenance and the smart factory," Deloitte, p. 8, 2017.

10. A. Rojko, "Industry 4.0 Concept: Background and Overview," Int. J. Interact. Mob. Technol., vol. 11, no. 5, pp. 77-90, 2017.

11. S. Mittal, M. A. Khan, D. Romero, and T. Wuest, "A critical review of smart manufacturing \& Industry 4.0 maturity models: Implications for small and medium-sized enterprises (SMEs)," J. Manuf. Syst., vol. 49, no. November, pp. 194-214, 2018. EC, "What is an SME?".

12. L. Sommer, "Industrial revolution Industry 4.0: Are German manufacturing SMEs the first victims of this revolution?," J. Ind. Eng. Manag., vol. 8, 2015. 